MATEC Web of Conferences 53, 01018 (2016)

DOI: $10.1051 /$ matecconf/20165301018

(C) Owned by the authors, published by EDP Sciences, 2016

\title{
Improvement of Energy Efficiency of Schools and Kindergartens
}

\author{
Danica Stankovic ${ }^{1, a}$ \\ ${ }^{1}$ University of Nis, Faculty of Civil Engineering and Architecture, Aleksandra Medvedeva st. 14, Nis, Serbia
}

\begin{abstract}
The paper exposes the reasons and methodology of energy efficiency improvement of schools and kindergartens as public facilities, which will give children the understanding of importance of such measures and it's positive impact on our planet. Modernization of educational institutions is targeted at ensuring positive dynamics for fuel and energy consumption reduction.
\end{abstract}

\section{1 introduction}

The significance of school and kindergartens for overall energy efficiency may be questioned. They are relatively small and rare as compared to other types of buildings. As such, they consume small part of overall energy which is spent in buildings. However, there are several good reasons for the improvement of energy efficiency in schools and kindergartens. Schools and kindergartens, as public facilities, should serve as an example to other buildings in the area of design and materialization, but also in promoting energy efficiency. Promoting the use of energy efficiency systems in public facilities is one of the best ways to implement such systems in private households and multifamily buildings [1-3]. The main occupants of the schools and kindergartens are children at the beginning of their journey through knowledge about the world. If we can explain meaning of renewable energy sources to children followed with real life examples that are put into their close environment we can be sure that earth is in good hands. Installation of energy efficiency systems is a process that can imply a lot of work [4-8]. Therefore, it would be a good idea to remodel schools and kindergartens along with the setting up of these systems, if their current ambient, functional or comfort properties are not satisfactory. So far, reconstruction of this type of buildings has been limited to necessary technical interventions, like repainting the walls and repairing the roofs. Functional organization and psychological factors have been mostly neglected, as well as improving energy efficiency.

\section{Reasons and methods of modernization}

Modernization of educational institutions is targeted at ensuring positive dynamics for fuel and energy consumption reduction. Reasons for the reconstruction [9-11]:

- the building's conditions are the technical reasons for the reconstruction. There are overheat energy losses through the walls, the windows, doors and roof of the school or kindergarten building;

${ }^{a}$ Corresponding author: danica0611@gmail.com 
- the socio-economics reasons for the reconstruction to be carried out are increased energy consumption in the building and municipality deficit budget stipulated inefficient comfort conditions in the school or kindergarten.

- The opportunities for energy efficiency in existing building are vary widely, depending on:

- the climate-zone where the building is located,

- $\quad$ the age of the building and the type of construction and

- the requirements and incentives involved [12, 13].

Educational institutions under control of Education Committee are located in 2278 buildings [14]. According to an analysis of technical and engineering status $80 \%$ of buildings have structural members, which need repairing. Since the requirements for energy consumption have been tightened practically all the existing schools have low energy efficiency class and need to be streamlined to reach significant reduction of thermal energy consumption.

The most significant reasons for the high energy consumption in school and kindergarten buildings are follows:

- $\quad$ the large losses in transportation through the systems for heating - through the dilapidated and inadequate isolated tube;

- $\quad$ awareness of energy as a valuable resource that should spend rational;

- $\quad$ low price does not contribute to the motivation for less consumption;

- factor of the heat loses through the windows;

- $\quad$ a lot of heat failure - inadequate external thermal insulation;

- $\quad$ lack radiator valves to regulate consumption in accordance with the temperature;

- $\quad$ inadequate electrical appliances that consume more electricity [12, 13].

The major measures that can be taken to achieve this aim are as follows:

- $\quad$ insulation of building envelopes;

- $\quad$ heat recovery ventilation systems $[15,16]$

- $\quad$ optimization of engineering equipment operation;

- installation of any types of meters and control of resources consumption.

The plan of the reconstruction includes:

- $\quad$ to change the windows,

- to change the outside doors,

- $\quad$ to install heat reflecting barriers and

- $\quad$ to install radiator's temperature regulators [13].

Let's take the school № 258 in Saint-Petersburg, which was repaired and where envelopes were insulated, as an example (Fig. 1) [14].
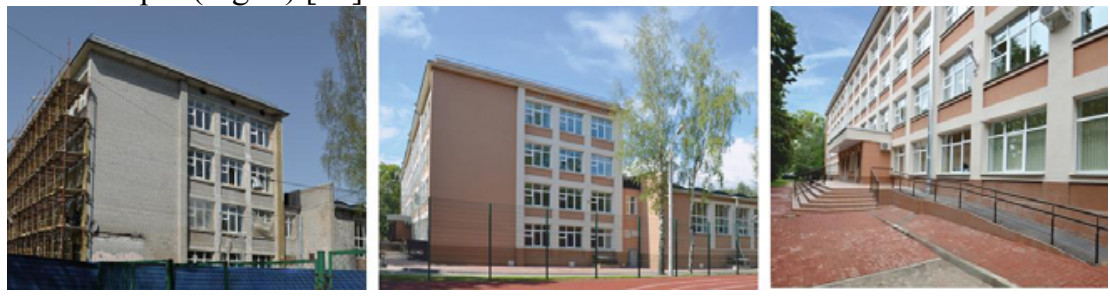

Figure 1. Secondary school № 258, Kolpinskiy district, Saint-Petersburg, before and after reconstruction, Kolpino, Pavlovskaya $80 \mathrm{~A}$

Expected results:

- $\quad$ increase thermal resistance of the windows,

- decrease heat loses factor of the windows,

- $\quad$ increase thermal resistance of the outside doors,

- decrease heat loses factor of the outside doors,

- decrease energy consumption for heating and hot water and

- $\quad$ improve comfort conditions of children in the school or kindergarten. 
The basic purpose of the reconstruction:

- $\quad$ to improve energy efficiency,

- $\quad$ to reduce energy consumption by reducing the heat looses of the building and

- $\quad$ decrease expenses for energy in the budget [13].

\subsection{Exterior walls insulation in case of buildings under reconstruction}

The most popular insulation method is given in Fig. 2 [14].

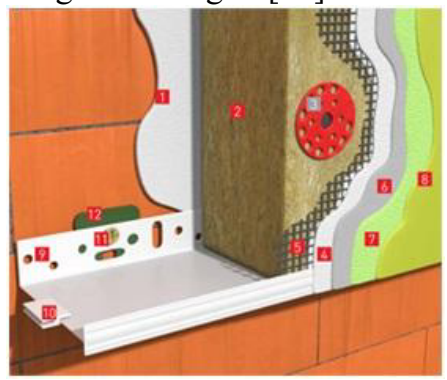

Figure 2. Insulation method for exterior walls; 1 - special adhesive mixture; 2 - rock wool insulated panels; 3 frontal expansion anchor stud; 4 - reinforcing filler; 5 - exterior glass cloth grid; 6 - water-dispersion primer; 7 decorative mineral plaster; 8 - frontal silicone paint; 9 - ground profile; 10 - mating element; 11 - ground anchor; 12 - roughness compensator

This method implies that a number of façade layers should be fixed to an exterior wall with the slabs made of rock wool serving as an insulator, and a thin finishing mortar with a reinforced pre-layer appears to be a façade layer. This method implies that a number of façade layers should be fixed to an exterior wall with the slabs made of rock wool serving as an insulator, and a thin finishing mortar with a reinforced pre-layer appears to be a façade layer [14].

\subsection{Improvement of energy efficiency through implementation of solar energy systems}

The use of solar energy systems is one of the primary strategies in modern sustainable architectural design. There are many possibilities for using active solar energy systems in both newly designed and reconstructed buildings. Architectural structures with integrated systems for renewable energy production have greater autonomy in energy usage and a higher degree of independence from public energy grid. Building-integrated solar system is ranked as one of the most prospective active green energy systems. The required pre-requisites for zero energy building construction can be created by the using of active building-integrated solar systems for independent energy supply of schools and preschool facilities. Active building-integrated solar systems can be divided into three groups, according to the type of energy produced: photovoltaic (PV) systems (BIPV) (Figure 3); thermal systems (BIST) (Figure 4); PV and thermal systems (BIPVT) [6, 7, 17, 18].

The use of solar energy systems is becoming predominant and essential part, not only of new building design, but also the existing building reconstruction design. These principles are especially important in the process of revitalization of the existing school and kindergartens which do not meet contemporary standards. Flexibility and wide range of possible use make these systems very convenient for preschool facilities. The use of solar collectors is fully justified and valid because of relatively high demands for sanitary hot water and low cost of solar collectors, which makes the return on investment in these systems very quick [19]. 


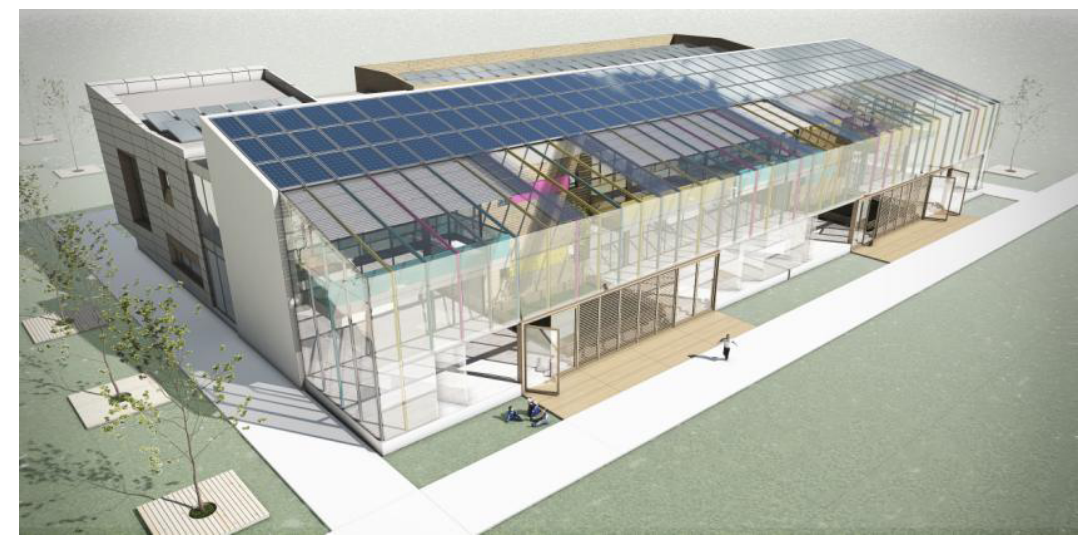

Figure 3. Example of photovoltaic system

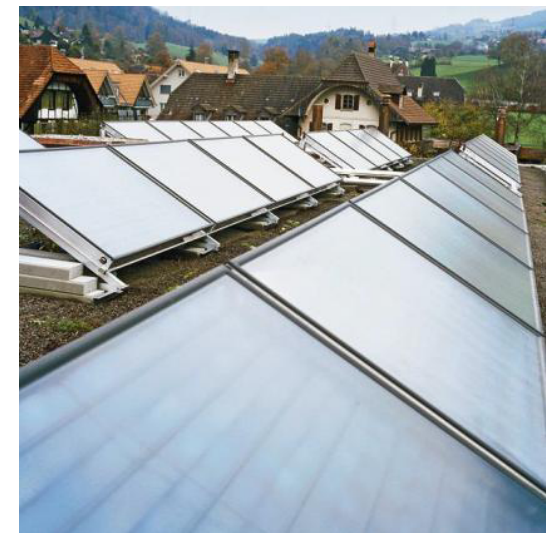

Figure 4. Example of thermal system

The result of significant spatial development in architectural plan is a large roof area which could provide great capacity in terms of space that could be used for installation of solar systems. Using roof for solar energy system installation could be a good strategy for transforming building disadvantage (unfavorable volume to building envelope area) into an advantage in terms of energy efficiency. Therefore, multifunctional roof treatment is desirable [12].

\subsection{Guidelines in the process of reconstruction of the internal environment - comfort improvement}

By implementing new technologies, existing materials of improved quality and the introduction of new environmentally friendly materials and equipment in the area of internal environment of schools and preschool facilities, comfort of the children is rising at a significantly higher development level.

Air comfort. The indoor quality of air that children breathe is of vital importance for their general health and development. Ventilation system is crucial for correct air comfort of the space occupied by children. Thus, comfort can be enhanced by improving ventilation system. Internal air comfort depends on indoor absence of pollutants i.e. ventilation systems which pump fresh air, and the power of filters to remove polluting substances, activities of kindergarten users and properties of materials applied to structural elements and accessories [18-20].

Special caution is needed when selecting proper surface and equipment finishing materials for interior surfaces such as floors, walls, ceilings and every other surface. It is strongly recommended 
avoiding using materials that release off-gas volatile organic compounds into the air, particularly formaldehyde-based finishes, adhesives, carpeting and particleboard.

When the given assignment refers to designing or revitalizing old schools and kindergarten, in order to ensure higher air quality, the key thing is predicting ventilation system with enough power and equipment, as well as devices for mechanical ventilation of certain areas (in the lobby area, toilets, etc.). It is also important to test all materials in order to determine the degree of their impact on air quality in rooms where children reside, prior to applying them as a final finish. Furthermore, materials which are used for making kindergarten furniture and other preschool accessories must undergo these tests.

Light comfort. Light comfort is defined by the following parameters: daylight, window position, window area, glazing types, etc. [19- 22]. Apart from the above mentioned parameters, light comfort is certainly affected by additional installed artificial lighting that comes from built-in light fittings. As for parameters of colour and intensity, artificial light should certainly be as close as possible to daylight. Additionally, it is advisable to install lighting system that will help improve visual comfort without any negative effects on children's vision. Avoiding the use of fluorescent lamps is strongly advisable as well. Apart from providing soft shadows and uniform light, fluorescent lamps produce negative flickering that has negative effect on children's health and their work abilities because it creates sense of embarrassment and discomfort.

Achieving visual comfort and more pleasant stay is reflected in correct amount of light that has been introduced to a room. Regarding the amount of luminance required in various indoor spaces in preschool facilities, current legislation and regulations in Serbia stipulate that parent units, i.e. rooms for group care, room lighting with artificial light sources should be 150lux for incandescent bulb and 250lux for fluorescent lamps, and 60lux for toilets with artificial lighting. In order to achieve more environmentally friendly building, replacement of old light bulbs with new and energy-efficient blubs that have significantly lower consumption of electricity is necessary [12].

Aesthetic comfort. Preschool children have the need for facilities that will aid them in physical and mental development. Space designed for children must meet certain requirements. In terms of aesthetic comfort, interior should be imaginative and attractive, abundant with content, with purposely designed areas (calm or dynamic interior depending on the purpose of the area purpose, e.g. sleeping or playing zones). Aesthetic comfort may be affected by a combination of: how the whole space appears to the eye, how materials feel to the touch, impression of whole kindergarten in combination with the surroundings, how it interacts with everyday users, how it is remembered and how children can manipulate it in order to create different space of their own [23, 24].

\section{Conclusion}

Achieving cheerful and pleasing experience of school and kindergarten interior areas is imperative for creating good educational environment and must be carried out through proper application of colour and texture, pleasant to the eye and touch. Therefore, the place where they spend a significant amount of time learning and having fun needs to meet their requirements for beautiful, imaginative and attractive space. Beside the need for aesthetically pleasing experience in space, interior environment should respond to children's needs for safe and secure environment. Complete experience of design has to be organized in a way which helps children experience and accept school and kindergarten as a second home. Viewed from the perspective of a child, interior structure of preschool building should be in proportion with children's abilities to percept space. Identification and recognition of interior space elements, their shapes, colours, and size play key role in appropriate perception of space [12].

The accompanying positive aspects of reconstruction could be:

the close co-operation with municipality representatives involved in energy conservation and efficient use sector;

- recommendation of the reconstruction could be identified as it may be of service to implement energy efficiency reconstructions in public building to ensure the energy efficiency, energy conservation and acceptable payback time of the reconstructions [13]. 


\section{References}

1. J. Ćetković, S. Rutešić, M. Zarković, M. Knežević, N. Vatin, Procedia Engineering, 117 (1), 780-790 (2015)

2. S.G. Popović, S. Vukanić, D.F. Komatina, E. Alihodzic-Jasarevic, N. Vatin, Procedia Engineering, 117 (1), 614-620 (2015)

3. M. Tanic, D. Stankovic, V. Nikolic, M. Nikolic, D. Kostic, A. Milojkovic, S. Spasic, N. Vatin, Procedia Engineering, 117 (1), 924-937 (2015)

4. V. Murgul, N. Vatin, E. Aronova, Applied Mechanics and Materials, 635-637, 2029-2035 (2014)

5. G. Radovic, V. Murgul, N.I. Vatin, Applied Mechanics and Materials, 584-586, 564-569 (2014)

6. V. Murgul, Journal of Applied Engineering Science, 12 (2), 121-128 (2014)

7. R. Alihodzic, V. Murgul, N. Vatin, E. Aronova, V. Nikolić, M. Tanić, D. Stanković, Applied Mechanics and Materials, 624, 604-612 (2014)

8. G. Radovic, V. Murgul, N. Vatin, E. Aronova, Applied Mechanics and Materials, 627, 357-364 (2014)

9. V. Murgul, Procedia Engineering, 117, 808-818 (2015)

10. V. Pukhkal, V. Murgul, M. Garifullin, Procedia Engineering, 117, 624-627 (2015)

11. M. Penić, N. Vatin, V. Murgul, Applied Mechanics and Materials, 680, 534-538 (2014)

12. D. Stankovic, Proceedings of 10th International Multidisciplinary Scientific Geo-Conference SGEM 2010, Sofia: STEF92 Technology Ltd., 2, 725- 731, (2010)

13. D. Stankovic, M. Tanic, et al., Revitalization of preschool facilities in Serbia, (Faculty of Civil Engineering and Architecture, University of Nis, (2014)

14. S. Golovina, Procedia Engineering, 117, 476-486 (2015)

15. V. Murgul, D. Vuksanovic, N. Vatin, V. Pukhkal, Applied Mechanics and Materials, 635-637, 370-376 (2014)

16. V. Pukhkal, N. Vatin, V. Murgul, Applied Mechanics and Materials, 680, 529-533 (2014)

17. E. Aronova, N. Vatin, V. Murgul, Procedia Engineering, 117, 771-779 (2015)

18. V. Murgul, D. Vuksanovic, N. Vatin, V. Pukhkal, Applied Mechanics and Materials, 680, 524$528(2014)$

19. V. Murgul, D. Vuksanovic, V. Pukhkal, N. Vatin, Applied Mechanics and Materials, 633-634, 977-981 (2014)

20. A. Milajić, D. Beljaković, D. Davidović, N. Vatin, V. Murgul, Procedia Engineering, 117, 916$923(2015)$

21. V. Murgul, N. Vatin, I. Zayats, Procedia Engineering, 117, 824-829 (2015)

22. S. Kosanović, A. Fikfak, Energy and Buildings, (2015)

23. I. Čerpes, N. Pandol, A. Fikfak, European Countryside, 6 (3), 225-242 (2014)

24. Leskovar, V.Ž., Premrov, M. Energy and Buildings, 43 (12), 3410-3418 (2011) 